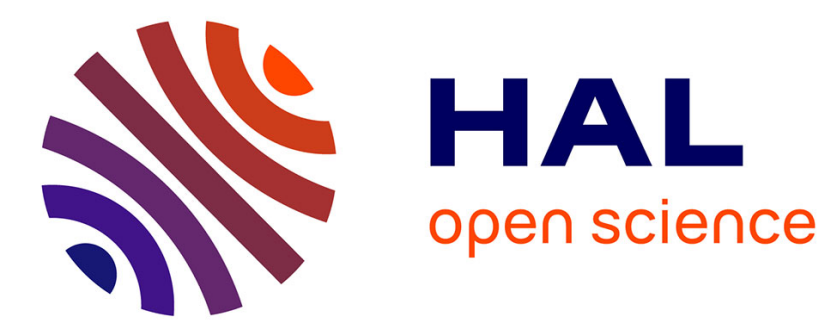

\title{
Three dimensional functional analysis of the human mandibular movements
}

Typhaine Koeppel, Emilie Sapin - de Brosses, Anne-Sophie Bonnet

\section{To cite this version:}

Typhaine Koeppel, Emilie Sapin - de Brosses, Anne-Sophie Bonnet. Three dimensional functional analysis of the human mandibular movements. Computer Methods in Biomechanics and Biomedical Engineering, 2015, French Society of Biomechanics, 18 (sup1), pp.1964-1965. 10.1080/10255842.2015.1069569 . hal-02121781

\section{HAL Id: hal-02121781 \\ https://hal.science/hal-02121781}

Submitted on 23 Apr 2021

HAL is a multi-disciplinary open access archive for the deposit and dissemination of scientific research documents, whether they are published or not. The documents may come from teaching and research institutions in France or abroad, or from public or private research centers.
L'archive ouverte pluridisciplinaire HAL, est destinée au dépôt et à la diffusion de documents scientifiques de niveau recherche, publiés ou non, émanant des établissements d'enseignement et de recherche français ou étrangers, des laboratoires publics ou privés. 


\title{
Three dimensional functional analysis of the human mandibular movements
}

\author{
T. Koeppel ${ }^{\mathrm{a}}$, E. Sapin-De Brosses ${ }^{\mathrm{a} *}$, and A-S. Bonnet ${ }^{\mathrm{a}}$ \\ ${ }^{a}$ Laboratoire de Mécanique Biomécanique Polymère Structures (LaBPS), Ecole Nationale d'Ingénieurs de Metz, \\ Université de Lorraine, 1 Route d'Ars Laquenexy, CS 65820, 57078, Metz Cedex 3, France;
}

Keywords: temporomandibular joint; kinematics

\section{Introduction}

Temporomandibular joint (TMJ) is composed by the temporal fossa (skull), the mandibular condyle and an articular disc in between. The analysis of the TMJ motions is complex since the left and right joints are simultaneously actuated, the articular disk moves relatively to both bony articular surfaces, and several translations and rotations are combined for each mouth movement. Many studies have quantified the path of mandibular points for elementary mouth movements (Ferrario et al. 2005) (Reicheneder et al. 2009) but no conclusions can be drawn, due to the lack of standardization for the choice of the bony landmarks and frames. Thus, the purpose of our study is to quantify the 3D kinematics of the mandible considered as a rigid body for healthy volunteers. Results are presented for sixteen subjects.

\section{Methods}

\subsection{Subjects}

Sixteen volunteers ( 8 men and 8 women, 22 to 45 years old) without muscular or dental pain, joint dysfunctions, orthodontic treatment or tooth replacement, were recruited. All subjects provided written informed consent to participate.

\subsection{Experimental procedure}

Mandibular movements were recorded using the CMS20-JMA device illustrated in figure 1 (Zebris Medizintechnik GmbH, Isny, Germany). The position of a mobile transmitter unit glued on the mandibular teeth, with respect to the receiving unit fixed on the head, was recorded. Bony landmarks were pointed on the skin. Their 3D coordinates were provided at each time in the skull frame described below. After one training test, the volunteers performed 10 trials of maximal openingclosing, lateral and forward-backward movements.

\subsection{Landmarks study}

The skull frame was based on left and right condylar points ( $\mathrm{LC}$ and $\mathrm{RC}$ ) and the right infraorbital point. The origin is the middle of the two condylar points. Y-axis is normal to the plane including the three points (upward), Z-axis passes through the condylar points (from LC to $\mathrm{RC}$ ) and $\mathrm{X}$-axis is the resulting cross product axis (forward). LC and RC, considered either as mandibular points or as corresponding temporal points, are deduced from the positions of the left and right superior tragus points (Reiber \& Dickbertel 1988). Similarly, the mandibular frame is based on LC, RC and the point between the first upper incisors (considered as a mandibular point and called IP below).

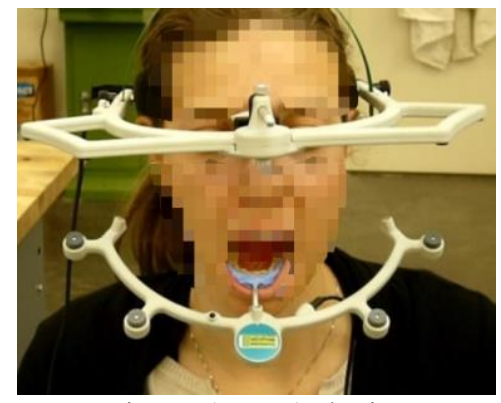

Figure 1: JMA device

\subsection{System accuracy}

The accuracy of the CMS-20-JMA system was assessed by comparing the translations and rotations to those given by a multi-axis translation and rotation stage (stage accuracy: $\pm 0.01 \mathrm{~mm}, \pm 0.5^{\circ}$ ). A maximal error of $0.26 \mathrm{~mm}$ was obtained for translations along $\mathrm{Y}$ and Zaxes (for ranges of $\pm 28 \mathrm{~mm}$ and $36 \mathrm{~mm}$ respectively). Maximal errors in rotation were $1.5^{\circ}$ around the $\mathrm{X}$-axis (range $\pm 18^{\circ}$ ) and $<0.5^{\circ}$ around the $\mathrm{Z}$-axis (range $36^{\circ}$ ).

\subsection{Data analysis}

Data analysis was performed using routines created with Matlab R2013a software (The MathWorks, Inc). Mandibular translations and rotations relative to the skull were computed at each time step using the (Y, X', Z') sequence for the rotations. To compare the results between the subjects, the movements with the largest magnitude were selected among the 10 trials.

The magnitude of the movements corresponded to the maximal displacement of IP along the superior-inferior axis for the maximal mouth opening (MMO), along the left-right axis for the maximal mouth lateral amplitude (MML), and along the backward-forward axis for the maximal mouth propulsion amplitude (MMP). The influence of subjects' morphology, gender and age on these magnitudes was tested using the Spearman rank test with a two-tailed level of significance of 0.05 ( $\rho$ parameter > 0.51). Partial correlation was tested when a

*Corresponding author. Email: emilie.de-brosses@ univ-lorraine.fr 
dependence between several parameters was expected. Dental occlusion influences the initial position and the above magnitudes. To quantify the effect of each mobility on the position of the teeth, the curvilinear path of IP due to the mandibular rotations and its linear path due to the translations were computed. Especially, the amount of rotation at the maximal mouth opening (\% Rot) corresponded to the IP curvilinear path due to the mandibular rotations divided by its total path (due to mandibular rotations and translations).

\section{Results and discussion}

The MMO is on average $39.7 \pm 5.8 \mathrm{~mm}$. This magnitude depends on the body height $(\rho=0.80)$ and slightly depends on the gender $(\rho=0.58)$. MMO does not depend on the age and weight, which is consistent with previous studies (Lewis et al. 2001). The average $\%$ Rot is $77.8 \pm 3.2 \%$ (range: 71 to $83 \%$ ). This value is in agreement with those of $76.86 \% \pm 4.20$ for women and $7.28 \% \pm 3.08$ for men reported in Ferrario's study. MML and MMP are on average $21.7 \pm 3.2 \mathrm{~mm}$ and $7.4 \pm 1.9 \mathrm{~mm}$ respectively. Contrary to the MMO, no correlation is found with subject's morphology, age or gender $(\rho<0.51)$. This may be due to the fact that lateral and forward movements are less constrained than opening movements and can be achieved in different ways, especially with different stages of opening.

The variations of the mandibular rotations and translations are quantified during mouth movements for all the subjects (mean \pm 1 standard deviation - see figure 2). During mouth opening movements, as well as during mouth propulsion, intercondylar rotation (Z), backward-forward (X) and superior-inferior (Y) translations are predominant. This can be compared with a $2 \mathrm{D}$ movement in the sagittal plane. However a left-right asymmetry is observed for each subject. For lateral movements, there are no predominant mobilities. The variability between subjects is larger for the intercondylar rotation and the forwardbackward translation. At each time step, rotation and translations simultaneously appear whatever the mouth movement (Kim et al. 2010).

\section{Conclusions}

Whatever the mouth movement, the 3D kinematics of TMJ is a combination of simultaneous rotations and translations.

MMO is correlated with body height, which is not true for the other magnitudes. As far as we know, this is the first study that quantifies the $3 \mathrm{D}$ mandibular motions for three different mouth movements. The conclusions are limited by the relative small number of volunteers currently included in the study, but the analysis will be continued. Further database could help to understand and identify TMJ dysfunctions

\section{Acknowledgements}

The authors wish to thank all the volunteers who participated in the study.

\section{References}

Ferrario VF, Sforza C, Lovecchio N, Mian F. 2005. Quantification of translational and gliding components in human temporomandibular joint during mouth opening. Arch Oral Biol. 50:507515.

Kim S-G, Kim D-S, Choi S-C, Lee S-S, Heo M-S, Huh K-H, Hwang S-J, Yi W-J. 2010. The relationship between three-dimensional principal rotations and mandibular deviation. Oral Surg Oral Med Oral Pathol Oral Radiol Endodontology. 110:e52-e60.

Lewis RP, Buschang PH, Throckmorton GS. 2001.

Sex differences in mandibular movements during opening and closing. Am J Orthod Dentofac Orthop Off Publ Am Assoc Orthod Its Const Soc Am Board Orthod. 120:294-303.

Reiber T, Dickbertel J. 1988. [Localization of the hinge axis points]. Dtsch Zahnärztliche $\mathrm{Z}$. 43:194-198.

Reicheneder CA, Proff P, Baumert U, Gedrange T. 2009. Growth-related differences in maximum laterotrusion and retrusion between children and adults. Angle Orthod. 79:265-270.

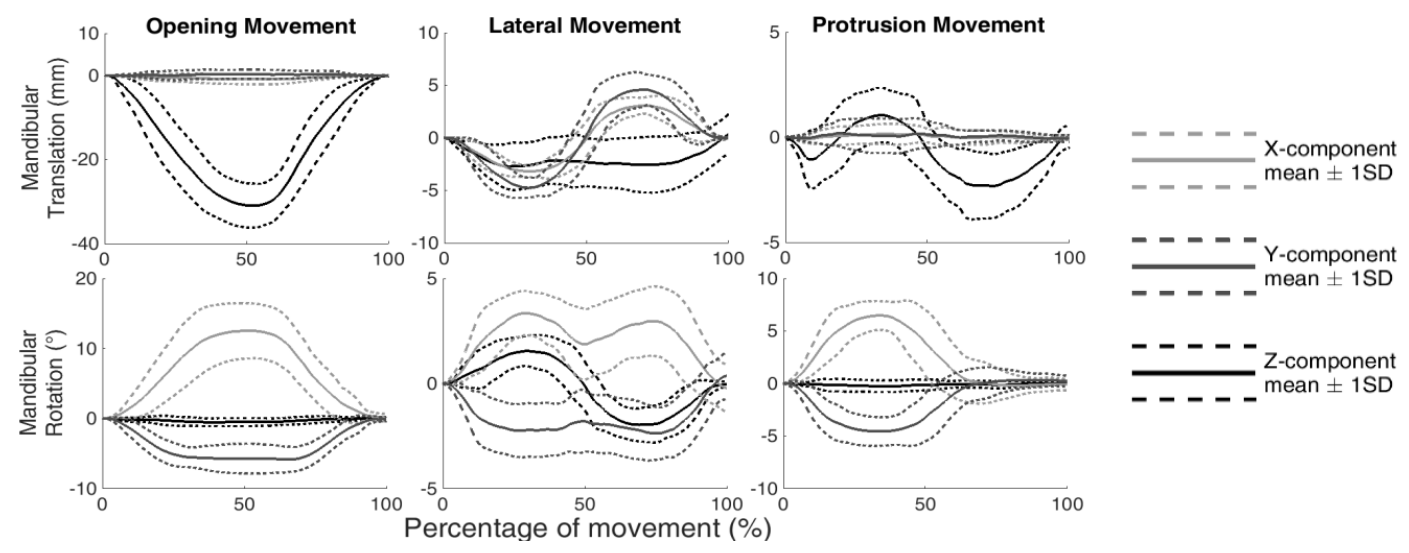

Figure 2 : TMJ mobilities 